\title{
Effect of outpatient therapy with inhaled corticosteroids on decreasing in-hospital mortality from pneumonia in patients with COPD
}

This article was published in the following Dove Press journal:

International Journal of COPD

23 June 2016

Number of times this article has been viewed

\author{
Yasuhiro Yamauchi' \\ Hideo Yasunaga ${ }^{2}$ \\ Wakae Hasegawa' \\ Yukiyo Sakamoto' \\ Hideyuki Takeshima' \\ Taisuke Jol,3 \\ Hiroki Matsui ${ }^{2}$ \\ Kiyohide Fushimi ${ }^{4}$ \\ Takahide Nagase' \\ 'Department of Respiratory Medicine, \\ Graduate School of Medicine, \\ ${ }^{2}$ Department of Clinical Epidemiology \\ and Health Economics, School of \\ Public Health, ${ }^{3}$ Division for Health \\ Service Promotion, The University of \\ Tokyo, ${ }^{4}$ Department of Health Policy \\ and Informatics, Tokyo Medical and \\ Dental University Graduate School \\ of Medicine, Tokyo, Japan
}

Correspondence: Yasuhiro Yamauchi Department of Respiratory Medicine, Graduate School of Medicine, The University of Tokyo,

7-3-I, Hongo, Bunkyo-ku, Tokyo

I | 3-8655, Japan

$\mathrm{Tel}+8 \mathrm{I} 3381554 \mathrm{II}$

Fax +8I 338155954

Email yamauchiy-int@h.u-tokyo.ac,jp
Background and objectives: Inhaled corticosteroids (ICS) and long-acting inhaled bronchodilators (IBD) are beneficial for the management of COPD. Although ICS has been reported to increase the risk of pneumonia in patients with COPD, it remains controversial whether it influences mortality. Using a Japanese national database, we examined the association between preadmission ICS therapy and in-hospital mortality from pneumonia in patients with COPD.

Methods: We retrospectively collected data from 1,165 hospitals in Japan on patients with COPD who received outpatient inhalation therapy and were admitted with pneumonia. Patients were categorized into those who received ICS with IBD and those who received IBD alone. We performed multivariate logistic regression analysis to examine the association between outpatient ICS therapy and in-hospital mortality, adjusting for the patients' backgrounds.

Results: Of the 7,033 eligible patients, the IBD alone group ( $n=3,331)$ was more likely to be older, have lower body mass index, poorer general conditions, and more severe pneumonia than the ICS with IBD group ( $n=3,702)$. In-hospital mortality was $13.2 \%$ and $8.1 \%$ in the IBD alone and the ICS with IBD groups, respectively. After adjustment for patients' backgrounds, the ICS with IBD group had significantly lower mortality than the IBD alone group (adjusted odds ratio, 0.80; 95\% confidence interval, 0.68-0.94). Higher mortality was associated with older age, being male, lower body mass index, poorer general status, and more severe pneumonia.

Conclusion: Outpatient inhaled ICS and IBD therapy was significantly associated with lower mortality from pneumonia in patients with COPD than treatment with IBD alone.

Keywords: inhaled corticosteroids, bronchodilators, in-hospital mortality, pneumonia, COPD

\section{Introduction}

COPD is the third leading cause of death in the world. ${ }^{1}$ COPD is characterized by persistent airflow restriction, which is associated with chronic airway inflammation. ${ }^{2}$ Mainstream treatments for COPD, as recommended by international guidelines, ${ }^{3}$ are mainly inhaled bronchodilators (IBD), including long-acting $\beta$ stimulants and long-acting muscarinic antagonists, to improve respiratory function and reduce respiratory symptoms, ${ }^{4-6}$ and inhaled corticosteroids (ICS) to reduce the frequency of exacerbations and improve the quality of life in patients with severe COPD. ${ }^{5,7,8}$ However, regular treatment with ICS does not modify the long-term decline of respiratory functions and mortality in COPD. ${ }^{9,10}$ Combination therapy with ICS and IBD is recommended for patients with severe COPD symptoms and frequent exacerbations. ${ }^{3}$ 
Recently, combination treatment with more than one long-acting IBD, consisting of long-acting $\beta$ stimulants and long-acting muscarinic antagonists without ICS, has been reported to be more effective in improving respiratory function and symptoms, ${ }^{11-13}$ and preventing exacerbations in severe $\mathrm{COPD}^{14}$ than use of IBD alone. In addition, withdrawal of ICS from treatment with triple combination therapy, consisting of long-acting $\beta$ stimulants, long-acting muscarinic antagonists, and ICS, does not change the risk of exacerbations. ${ }^{15}$ This suggests that combined IBD treatment would be as effective in preventing exacerbations as triple combination therapy. Thus, the benefits of ICS in the treatment of COPD have been questioned, particularly because of the adverse side effect of ICS-caused pneumonia.

Lower respiratory infections, such as pneumonia, often occur in COPD and are known to cause COPD exacerbations, increasing the risk of mortality. ${ }^{16,17}$ In addition, recent clinical studies and meta-analyses have reported that ICS use increases the occurrence of pneumonia. ${ }^{18-21}$ Other studies have produced conflicting results regarding the rate of mortality from pneumonia in patients with COPD using ICS as outpatients. ${ }^{18,22-24}$ Thus, it is important and useful for the management of COPD to clarify the association between ICS and mortality from pneumonia in patients with COPD.

This study aimed to examine the association between ICS and mortality from pneumonia in patients with COPD by comparing in-hospital mortality between those who received ICS with IBD and those who received IBD alone.

\section{Methods}

\section{Database}

We used the Japanese diagnosis procedure combination database, which contains administrative claims data and discharge abstract data from approximately 7,000,000 inpatients per year from around 1,100 hospitals across Japan. The database also includes the outpatient data of patients admitted to 426 hospitals. The database does not include data about those patients who only received outpatient treatment.

The inpatient database contains details of the primary diagnosis on admission, comorbidities present on admission, and complications occurring during hospitalization. These are recorded with the appropriate International Classification of Disease and Related Health Problems, 10th revision (ICD-10) codes accompanied by text in Japanese. This database also contains the following information on admission: dates of admission and discharge; intensive care unit admission during hospitalization; discharge status; the patient's age, sex, body height, and weight; severity of dyspnea based on the Hugh-Jones dyspnea scale, ${ }^{25,26}$ levels of consciousness based on the Japan Coma Scale; ${ }^{27,28}$ activities of daily life on admission converted to the Barthel index; ${ }^{29}$ and severity of pneumonia based on age, dehydration, respiratory failure, orientation disturbance, and low blood pressure (A-DROP) score. ${ }^{30}$ Details of the Hugh-Jones dyspnea scale, the Japan Coma Scale, the Barthel index, and the A-DROP score are described in the "Supplementary materials". The database also includes data on the medication and procedures the patients received during hospitalization, for example, the administration of systemic corticosteroids and intubation/ mechanical ventilation. The outpatient data contain information that includes prescription dates and the names of the drugs prescribed.

This study was approved by the Institutional Review Board of The University of Tokyo. The board waived the requirement for the patients' written informed consent because of the anonymous nature of the data.

\section{Patient selection}

Inclusion criteria for this study were as follows: 1) patients aged over 40 years, 2) those who were admitted to hospital for pneumonia (ICD-10 codes, J10-J18, J69) as the primary diagnosis between July 1, 2010 and March 31, 2013, 3) those who had a secondary diagnosis of COPD (J41-44); and 4) those who received IBD.

We excluded 1) patients who received ICS alone; 2) those who had other obstructive ventilatory impairments, including bronchiectasis (J47) and diffuse panbronchiolitis (J21); and 3) those who had pneumonia recorded as a complication during hospitalization, to preclude hospital-acquired and ventilator-associated pneumonia (J95).

\section{Categorization by inhaled therapy}

The IBD administered included tiotropium, glycopyrronium, acridinium, umeclidinium, salmeterol, formoterol, indacaterol, and vilanterol. The ICS administered included fluticasone, budesonide, mometasone, and beclomethasone. Patients who received any ICS with any IBD were defined as the ICS with IBD group. Patients who received one or more IBD but did not receive any ICS were defined as the IBD alone group.

\section{A-DROP score}

We used the A-DROP scoring system to evaluate the severity of pneumonia. This system was established by the Japanese Respiratory Society and is similar to the CURB-65 system used by the British Thoracic Society. ${ }^{30}$ The severity of 
pneumonia was classified into four classes using the A-DROP score: mild, 0 points; moderate, $1-2$ points; severe, 3 points; and extremely severe, 4-5 points.

\section{Outcomes}

The primary outcome of this study was all-cause in-hospital mortality. The secondary outcomes were length of stay, length of intensive care unit stay, requirement for intubation/ mechanical ventilation, duration of mechanical ventilation, and mortality in patients who underwent mechanical ventilation during their hospital stay.

\section{Analysis}

We used the chi-square test to compare proportional data, the two-sample $t$-test to compare average values, and the Mann-Whitney $U$-test to compare the median values between groups. We performed multivariate logistic regression analyses to assess the association between ICS use and in-hospital mortality with adjustment for patients' backgrounds, while also adjusting for within-hospital clustering by means of generalized estimation equations. The threshold for significance was $P<0.05$. We performed all statistical analysis using SPSS statistics for Windows, version 22.0 (IBM Corporation, Armonk, NY, USA).

\section{Results}

We identified 7,033 patients with COPD (aged $\geq 40$ years) who were treated with outpatient inhaled therapy and were admitted to the hospital with pneumonia. Of them, 3,702 patients were treated with ICS and IBD, and 3,331 patients were treated with IBD alone. The patients' characteristics are shown in Table 1. A-DROP scores in the ICS and IBD group

Table I Clinical characteristics of patients on admission

\begin{tabular}{|c|c|c|c|c|}
\hline & \multirow{2}{*}{$\frac{\text { Total }}{(n=7,033)(\%)}$} & \multirow{2}{*}{$\frac{\text { ICS with IBD }}{(n=3,702)(\%)}$} & \multirow{2}{*}{$\frac{\text { IBD alone }}{(n=3,331)(\%)}$} & \multirow[t]{2}{*}{$P$-value } \\
\hline & & & & \\
\hline Age (years) ${ }^{a}$ & $76.3(8.4)$ & $75.7(8.4)$ & $77.0(8.4)$ & $<0.001$ \\
\hline Sex (male) & $6,315(89.8)$ & $3,281(88.6)$ & $3,034(91.1)$ & 0.001 \\
\hline \multicolumn{2}{|l|}{ BMI $\left(\mathrm{kg} / \mathrm{m}^{2}\right)$} & & & $<0.001$ \\
\hline$<18.5$ & $3,316(47.1)$ & $\mathrm{I}, 83 \mathrm{I}(49.5)$ & $\mathrm{I}, 485(44.6)$ & \\
\hline $18.5-24.9$ & $2,499(35.5)$ & $1,247(33.7)$ & $1,252(37.6)$ & \\
\hline $25.0-29.9$ & $492(7.0)$ & $266(7.2)$ & $226(6.8)$ & \\
\hline$\geq 30.0$ & $5 \mathrm{I}(0.7)$ & $18(0.5)$ & $33(1.0)$ & \\
\hline Missing & $675(9.6)$ & $340(9.2)$ & $335(10.1)$ & \\
\hline \multicolumn{2}{|c|}{ Dyspnea scale by Hugh-Jones classification } & & & $<0.001$ \\
\hline 1 & $607(8.6)$ & $301(8.1)$ & $306(9.2)$ & \\
\hline II & $897(12.8)$ & $460(12.4)$ & $437(13.1)$ & \\
\hline III & $\mathrm{I}, 07 \mathrm{I}(15.2)$ & $574(15.5)$ & $497(14.9)$ & \\
\hline IV & $1,913(27.2)$ & $1,095(29.6)$ & $818(24.6)$ & \\
\hline V & $\mathrm{I}, 754(4.9)$ & $922(24.9)$ & $832(25.0)$ & \\
\hline Unclassified & 791 (1I.2) & $350(9.5)$ & $44 \mid(13.2)$ & \\
\hline \multicolumn{2}{|c|}{ Activity of daily living by Barthel index } & & & $<0.001$ \\
\hline Completely independent & $2,275(32.3)$ & $\mathrm{I}, 247(33.7)$ & $1,028(30.9)$ & \\
\hline Partially independent & $\mathrm{I}, 064(15.1)$ & $604(16.3)$ & $460(13.8)$ & \\
\hline Partially dependent & $\mathrm{I}, 295(18.4)$ & $681(18.4)$ & $614(18.4)$ & \\
\hline Completely dependent & $1,163(16.5)$ & $534(14.4)$ & $629(18.9)$ & \\
\hline Missing & $1,263(17.6)$ & $636(17.2)$ & $600(18.0)$ & \\
\hline \multicolumn{2}{|c|}{ Level of consciousness by Japan Coma Scale } & & & $<0.001$ \\
\hline Clear & $6,338(90.1)$ & $3,398(91.8)$ & $2,940(88.3)$ & \\
\hline Dull & $54 \mid(7.7)$ & $240(6.5)$ & $301(9.0)$ & \\
\hline Somnolence & $100(1.4)$ & $4 I(I . I)$ & $59(1.8)$ & \\
\hline Coma & $53(0.8)$ & $23(0.6)$ & $30(0.9)$ & \\
\hline \multicolumn{2}{|c|}{ Pneumonia severity by A-DROP score } & & & $<0.001$ \\
\hline Mild & $416(5.9)$ & $222(6.0)$ & $194(5.8)$ & \\
\hline Moderate & $3,349(47.6)$ & $1,808(48.8)$ & $1,541(46.3)$ & \\
\hline Severe & $978(13.9)$ & $501(13.5)$ & $477(14.3)$ & \\
\hline Extremely severe & $301(4.3)$ & $122(3.3)$ & $179(5.4)$ & \\
\hline Missing & $1,989(28.3)$ & $\mathrm{I}, 049(28.3)$ & $940(28.2)$ & \\
\hline
\end{tabular}

Notes: a Mean (SD). The two-sample $t$-test was used to compare average values between groups. The chi-square test was used to compare proportional data between groups. The threshold for significance was a value of $P<0.05$.

Abbreviations: A-DROP, age, dehydration, respiratory failure, orientation disturbance, and low blood pressure; BMI, body mass index; IBD, inhaled bronchodilators; ICS, inhaled corticosteroids; SD, standard deviation. 
Table 2 Patient comorbidities on admission

\begin{tabular}{|c|c|c|c|c|}
\hline & Total & ICS with IBD & IBD alone & $P$-value \\
\hline & $(n=7,033)(\%)$ & $(n=3,702)(\%)$ & $(n=3,331)(\%)$ & \\
\hline Asthma & I,872 (26.6) & $1,379(37.3)$ & $493(14.8)$ & $<0.001$ \\
\hline Interstitial pneumonia & $323(4.6)$ & $125(3.4)$ & $198(5.9)$ & $<0.001$ \\
\hline Lung cancer & $719(10.2)$ & $261(7.1)$ & $458(13.7)$ & $<0.001$ \\
\hline Congestive heart failure & $\mathrm{I}, 223(\mathrm{I} 7.4)$ & $597(16.1)$ & $626(18.8)$ & 0.003 \\
\hline Arrhythmia & $331(4.7)$ & $157(4.2)$ & $174(5.2)$ & 0.052 \\
\hline Cerebrovascular disease & $299(4.3)$ & $15 \mid(4.1)$ & $148(4.4)$ & 0.450 \\
\hline Chronic liver disease & $86(1.2)$ & $38(1.0)$ & $4(1.4)$ & 0.114 \\
\hline Chronic renal failure & $133(1.9)$ & $61(1.6)$ & $72(2.2)$ & 0.114 \\
\hline
\end{tabular}

Notes: The chi-square test was used to compare proportional data between groups. The threshold for significance was a value of $P<0.05$.

Abbreviations: IBD, inhaled bronchodilators; ICS, inhaled corticosteroids.

were significantly lower, and therefore their pneumonia was less severe, than in the IBD alone group.

Comorbidities on admission are presented in Table 2. The percentage of asthma was higher in the ICS and IBD group than in the IBD alone group. The percentages of interstitial pneumonia, lung cancer, and congestive heart failure were lower in the ICS and IBD group.

The outcomes are shown in Table 3. All-cause inhospital mortality in the ICS and IBD group was $8.1 \%$, which was significantly lower than that in the IBD alone group (13.2\%). Length of stay in the ICS and IBD group was shorter than that in the IBD alone group. The difference in the results for intensive care unit admission or requirement for mechanical ventilation was not significant between the groups. In-hospital mortality in patients who required mechanical ventilation was significantly lower in the ICS and IBD group $(31.9 \%, \mathrm{n}=100 / 313)$ than in the IBD alone group $(39.7 \%, \mathrm{n}=129 / 325)$.

The results of multivariate logistic regression analysis for all-cause in-hospital mortality associated with pneumonia in patients with COPD are shown in Table 4. Outpatient treatment with ICS and IBD was significantly associated with lower mortality than IBD treatment alone, even after adjustment for the patients' backgrounds. Higher mortality was associated with being male, lower body mass index (BMI), severe dyspnea, poorer activities of daily living scores, and more severe pneumonia. Higher mortality was also associated with having interstitial pneumonia and lung cancer, whereas lower mortality was associated with having asthma.

\section{Discussion}

We demonstrated that in-hospital mortality associated with pneumonia in patients with COPD was significantly lower in patients treated with combined ICS and IBD therapy than IBD alone.

Previous studies have reported that the use of ICS in patients with COPD increased the occurrence of serious pneumonia requiring hospitalization. ${ }^{18-21}$ However, the association between ICS use and mortality from pneumonia in patients with COPD has remained controversial. One study demonstrated that the use of ICS was associated with an increased risk of hospitalization for pneumonia and subsequent death. ${ }^{18}$ Several studies have reported that the use of ICS had no impact on outcomes in patients with COPD admitted with pneumonia. ${ }^{19,21,22}$ Other studies have demonstrated that ICS use was associated with a decreased risk of mortality, after adjusting for potential confounders, including age, sex,

Table 3 Clinical course and outcomes

\begin{tabular}{|c|c|c|c|c|}
\hline & Total & ICS with IBD & IBD alone & $P$-value \\
\hline & $(n=7,033)(\%)$ & $(n=3,702)(\%)$ & $(n=3,33 I)(\%)$ & \\
\hline Death, n (\%) & $742(10.6)$ & $30 I(8.1)$ & $44 \mid(\mid 3.2)$ & $<0.001$ \\
\hline Length of stay (days), median (IQR) & $15(10-25)$ & $14(10-23)$ & $15(10-26)$ & $<0.001$ \\
\hline Systemic corticosteroids, n (\%) & $20(0.3)$ & $12(0.3)$ & $8(0.2)$ & 0.509 \\
\hline ICU admission, n (\%) & $|5|(2.1)$ & $8 \mathrm{I}(2.2)$ & $70(2.1)$ & 0.803 \\
\hline ICU stay (days), median (IQR) & $5(2-10)$ & $5(1.5-10)$ & $4.5(2-12)$ & 0.577 \\
\hline Mechanical ventilation, $\mathrm{n}(\%)$ & $638(9.1)$ & $313(8.5)$ & $325(9.8)$ & 0.058 \\
\hline Length of MV (days), median (IQR) & $8(2-23)$ & $7(2-20.5)$ & $8(2.5-25)$ & 0.202 \\
\hline Deaths among patients under MV ( $n=638) ; n(\%)$ & $229(35.9)$ & $100(31.9)$ & $129(39.7)$ & 0.042 \\
\hline
\end{tabular}

Notes: The chi-square test was used to compare proportional data between groups. The Mann-Whitney U-test was used to compare the median values between groups. The threshold for significance was a value of $P<0.05$.

Abbreviations: IBD, inhaled bronchodilators; ICS, inhaled corticosteroids; ICU, intensive care unit; IQR, interquartile range; MV, mechanical ventilation. 
Table 4 Multivariate logistic regression analysis for in-hospital mortality

\begin{tabular}{|c|c|c|c|c|}
\hline IBD alone & $\begin{array}{l}\text { Adjusted odds ratio } \\
\text { Reference }\end{array}$ & \multicolumn{2}{|c|}{ 95\% Confidence interval } & $P$-value \\
\hline ICS and IBD & 0.80 & 0.68 & 0.94 & 0.007 \\
\hline \multicolumn{5}{|l|}{ Age (years) } \\
\hline $40-64$ & Reference & & & \\
\hline $65-74$ & $1.5 \mathrm{I}$ & 1.04 & 2.20 & 0.033 \\
\hline $75-84$ & 1.36 & 0.93 & 1.99 & 0.116 \\
\hline$>85$ & 2.12 & 1.40 & 3.24 & $<0.001$ \\
\hline \multicolumn{5}{|l|}{ Sex } \\
\hline Male & Reference & & & \\
\hline Female & 0.66 & 0.48 & 0.90 & 0.008 \\
\hline \multicolumn{5}{|l|}{ BMI $\left(\mathrm{kg} / \mathrm{m}^{2}\right)$} \\
\hline$<18.5$ & 2.26 & 1.84 & 3.46 & $<0.001$ \\
\hline $18.5-24.9$ & Reference & & & \\
\hline $25-29.9$ & 0.75 & 0.47 & 1.18 & 0.216 \\
\hline$\geq 30$ & 1.26 & 0.38 & 4.18 & 0.749 \\
\hline Missing & 2.49 & 1.93 & 3.22 & $<0.001$ \\
\hline \multicolumn{5}{|l|}{ Dyspnea classification } \\
\hline 1 & Reference & & & \\
\hline II & 0.72 & 0.34 & 1.54 & 0.394 \\
\hline III & 1.21 & 0.70 & 2.09 & 0.290 \\
\hline IV & 1.86 & 1.08 & 3.20 & 0.026 \\
\hline V & 4.08 & 2.42 & 6.86 & $<0.001$ \\
\hline Unspecified & 4.55 & 2.68 & 7.71 & $<0.001$ \\
\hline \multicolumn{5}{|l|}{ Level of consciousness } \\
\hline Clear & Reference & & & \\
\hline Dull & 1.29 & 0.98 & 1.70 & 0.073 \\
\hline Somnolence & 2.28 & 1.50 & 3.48 & $<0.001$ \\
\hline Coma & 2.96 & 1.57 & 5.59 & 0.001 \\
\hline \multicolumn{5}{|l|}{ Activity of daily living } \\
\hline Completely independent & Reference & & & \\
\hline Partially independent & 0.97 & 0.67 & 1.40 & 0.871 \\
\hline Partially dependent & 1.55 & 1.12 & 2.14 & 0.009 \\
\hline Completely dependent & 3.03 & 2.21 & 4.16 & $<0.001$ \\
\hline Missing & 1.44 & 1.03 & 2.01 & 0.033 \\
\hline \multicolumn{5}{|l|}{ Severity of pneumonia } \\
\hline Mild & Reference & & & \\
\hline Moderate & 1.52 & 0.72 & 3.19 & 0.270 \\
\hline Severe & 2.83 & 1.29 & 6.20 & 0.010 \\
\hline Very severe & 7.41 & 3.24 & 16.95 & $<0.001$ \\
\hline Missing & 3.10 & 1.48 & 6.49 & 0.003 \\
\hline Systemic corticosteroids & 0.96 & 0.24 & 3.84 & 0.948 \\
\hline \multicolumn{5}{|l|}{ Comorbidities } \\
\hline Asthma & 0.57 & 0.45 & 0.73 & $<0.001$ \\
\hline Interstitial pneumonia & 1.92 & 1.29 & 2.86 & 0.001 \\
\hline Lung cancer & 3.57 & 2.74 & 4.65 & $<0.001$ \\
\hline Chronic heart failure & 1.24 & 1.00 & 1.54 & 0.047 \\
\hline Arrhythmia & 1.10 & 0.74 & 1.63 & 0.639 \\
\hline Cerebrovascular disease & 0.72 & 0.48 & 1.10 & 0.128 \\
\hline Chronic liver disease & 0.95 & 0.39 & 2.33 & 0.918 \\
\hline Chronic renal failure & 1.37 & 0.77 & 2.43 & 0.292 \\
\hline
\end{tabular}

Notes: The multivariate logistic regression analyses were used to assess the association between ICS use and in-hospital mortality. The threshold for significance was a value of $P<0.05$.

Abbreviations: BMI, body mass index; IBD, inhaled bronchodilators; ICS, inhaled corticosteroids.

and comorbidities. ${ }^{23,24}$ Furthermore, some of the previous studies $^{18,19}$ subjected the COPD patients who were taking inhaled therapy and evaluated the mortality of pneumonia, and the others ${ }^{22-24}$ subjected the COPD patients who were admitted with pneumonia and evaluated the effects of prior use of
ICS on mortality; these latter studies were compatible with our study. However, these studies were limited because they did not adjust for the severity of pneumonia. ${ }^{23,24}$ Our study confirmed that the outpatient usage of ICS was associated with lower mortality than nonusage of ICS, even after adjusting 
for several confounders, including pneumonia severity. This indicates that treatment with ICS has protective effects against pneumonia-related mortality in patients with COPD.

A possible explanation for the association between ICS and decreased mortality is that corticosteroids produce antiinflammatory effects by modulating inflammatory mediators. ICS may suppress the inflammatory response in the airway, which spreads to cause systemic inflammation. ${ }^{31}$ It may reduce systemic inflammation by blocking excessive inflammation and the harmful effects this causes during infections. $^{32}$

Our study demonstrated that A-DROP scores in patients receiving outpatient ICS treatment were lower than those not receiving ICS. A previous study with a relatively small sample size $(n=490)$ demonstrated that ICS use was not associated with pneumonia severity. ${ }^{22}$ Another previous study demonstrated that the use of ICS was associated with a lower degree of pleural inflammatory effusion, ${ }^{33}$ suggesting that ICS has a protective effect against the progression of pneumonia and related complications. Because ICS has been reported to reduce bacterial invasion into the airway epithelium in an experimental model ${ }^{34}$ and has the potential to reduce inflammation, prior use of ICS may lead to less severe pneumonia. Our study suggests that ICS may have protective effects against the progression of pneumonia in patients with COPD.

The association between ICS and mechanical ventilation has also been controversial. ${ }^{22,24}$ Our study demonstrated that the percentage of patients requiring mechanical ventilation was lower in the ICS and IBD group than in the IBD alone group, although this result was not significant. Furthermore, the mortality from pneumonia in patients with COPD requiring mechanical ventilation was significantly lower in the ICS and IBD group than in the IBD alone group. These results also suggest that ICS may have protective effects against pneumonia and pneumonia-related mortality in patients with COPD.

Comorbidity of asthma was associated with decreased mortality in this study. Recently, comorbid asthma and COPD have been recognized as asthma-COPD overlap (ACO). ${ }^{35}$ As patients with ACO have lower health-related quality of life, frequent exacerbations, and often require hospitalization, ${ }^{36,37}$ patients with ACO have been suggested to have a poorer long-term prognosis, when compared with patients having asthma or COPD alone. However, recent studies have demonstrated that ACO patients have better short-term mortality, compared with COPD alone. ${ }^{38,39}$ Our present study is consistent with the previous reports that comorbid asthma and COPD were associated with better prognosis.
Higher mortality was associated with worse general conditions at admission, including lower BMI, more severe dyspnea grade, lower level of consciousness, and poorer activities of daily life. The findings of this study were compatible with the previous study demonstrating the mortality of pneumonia in patients with COPD. ${ }^{26}$ Further, missing data in the covariants, such as BMI and activities of daily life at admission, were also associated with higher mortality in this study. Because patients with severe conditions might not be able to get their body height and weight measured or their physical activities evaluated at admission, missing data of BMI and activities of daily life might indicate the more severe general conditions.

This study has several limitations. First, the database did not contain information on the degree of airflow limitation, such as details of pulmonary function tests and COPD severity. However, the grade of dyspnea was used as a covariant of respiratory condition in this study, as a previous study had shown that dyspnea grade reflects respiratory function. ${ }^{40}$ Second, the database did not contain information related to the dosages of the medications used. Thus, we cannot evaluate the association between mortality and the dose of ICS.

\section{Conclusion}

Outpatient inhaled therapy with ICS and IBD was associated with lower mortality from pneumonia in patients with COPD than IBD treatment alone. ICS may have protective effects against pneumonia and help prevent pneumonia-related mortality in patients with COPD.

\section{Acknowledgment}

This work was supported in part by grants-in-aid for Scientific Research from the Ministry of Education, Science, Sports, Culture and Technology of Japan (YY, 15K09211; TN, 16H02653), grant to the Respiratory Failure Research Group, and grants for Research on Policy Planning and Evaluation from the Ministry of Health, Labour, and Welfare, Japan (grant numbers: H28-Policy-Designated-009 and H27-Policy- Strategy-011).

\section{Disclosure}

The authors report no conflicts of interest in this work.

\section{References}

1. World Health Organization, 20 June 2013. The top 10 causes of death. Available from: http://www.who.int/mediacentre/factsheets/fs310/en/. Accessed March 14, 2014.

2. Hogg JC, Chu F, Utokaparch S, et al. The nature of small-airway obstruction in chronic obstructive pulmonary disease. $N$ Engl J Med. 2004; 350:2645-2653. 
3. Vestbo J, Hurd SS, Agusti AG, et al. Global strategy for the diagnosis, management, and prevention of chronic obstructive pulmonary disease: GOLD executive summary. Am J Respir Crit Care Med. 2013;187: 347-365.

4. Tashkin DP, Fabbri LM. Long-acting beta-agonists in the management of chronic obstructive pulmonary disease: current and future agents. Respir Res. 2010;11:149.

5. Calverley PM, Anderson JA, Celli B, et al. Salmeterol and fluticasone propionate and survival in chronic obstructive pulmonary disease. N Engl J Med. 2007;356:775-789.

6. Tashkin DP, Celli B, Senn S, et al. A 4-year trial of tiotropium in chronic obstructive pulmonary disease. N Engl J Med. 2008;359:1543-1554.

7. Spencer S, Calverley PM, Burge PS, Jones PW. Impact of preventing exacerbations on deterioration of health status in COPD. Eur Respir J. 2004;23:698-702.

8. Szafranski W, Cukier A, Ramirez A, et al. Efficacy and safety of budesonide/formoterol in the management of chronic obstructive pulmonary disease. Eur Respir J. 2003;21:74-81.

9. Pauwels RA, Lofdahl CG, Laitinen LA, et al. Long-term treatment with inhaled budesonide in persons with mild chronic obstructive pulmonary disease who continue smoking. European Respiratory Society Study on Chronic Obstructive Pulmonary Disease. $N$ Engl J Med. 1999;340:1948-1953.

10. Vestbo J, Sorensen T, Lange P, Brix A, Torre P, Viskum K. Long-term effect of inhaled budesonide in mild and moderate chronic obstructive pulmonary disease: a randomised controlled trial. Lancet. 1999; 353:1819-1823.

11. van Noord JA, Aumann JL, Janssens E, et al. Comparison of tiotropium once daily, formoterol twice daily and both combined once daily in patients with COPD. Eur Respir J. 2005;26:214-222.

12. Tashkin DP, Pearle J, Iezzoni D, Varghese ST. Formoterol and tiotropium compared with tiotropium alone for treatment of COPD. COPD. 2009;6:17-25.

13. Bateman ED, Ferguson GT, Barnes N, et al. Dual bronchodilation with QVA149 versus single bronchodilator therapy: the SHINE study. Eur Respir J. 2013;42:1484-1494.

14. Wedzicha JA, Decramer M, Ficker JH, et al. Analysis of chronic obstructive pulmonary disease exacerbations with the dual bronchodilator QVA149 compared with glycopyrronium and tiotropium (SPARK) a randomised, double-blind, parallel-group study. Lancet Respir Med. 2013;1:199-209.

15. Magnussen H, Disse B, Rodriguez-Roisin R, et al. Withdrawal of inhaled glucocorticoids and exacerbations of COPD. $N$ Engl J Med. 2014;371:1285-1294.

16. Restrepo MI, Mortensen EM, Pugh JA, Anzueto A. COPD is associated with increased mortality in patients with community-acquired pneumonia. Eur Respir J. 2006;28:346-351.

17. Hasegawa W, Yamauchi Y, Yasunaga H, et al. Factors affecting mortality following emergency admission for chronic obstructive pulmonary disease. BMC Pulm Med. 2014;14:151.

18. Ernst P, Gonzalez AV, Brassard P, Suissa S. Inhaled corticosteroid use in chronic obstructive pulmonary disease and the risk of hospitalization for pneumonia. Am J Respir Crit Care Med. 2007;176:162-166

19. Joo MJ, Au DH, Fitzgibbon ML, Lee TA. Inhaled corticosteroids and risk of pneumonia in newly diagnosed COPD. Respir Med. 2010;104: 246-252.

20. Suissa S, Patenaude V, Lapi F, Ernst P. Inhaled corticosteroids in COPD and the risk of serious pneumonia. Thorax. 2013;68:1029-1036.
21. Singh S, Amin AV, Loke YK. Long-term use of inhaled corticosteroids and the risk of pneumonia in chronic obstructive pulmonary disease: a meta-analysis. Arch Intern Med. 2009;169:219-229.

22. Singanayagam A, Chalmers JD, Akram AR, Hill AT. Impact of inhaled corticosteroid use on outcome in COPD patients admitted with pneumonia. Eur Respir J. 2011;38:36-41.

23. Malo de Molina R, Mortensen EM, Restrepo MI, Copeland LA, Pugh MJ, Anzueto A. Inhaled corticosteroid use is associated with lower mortality for subjects with COPD and hospitalised with pneumonia. Eur Respir J. 2010;36:751-757.

24. Chen D, Restrepo MI, Fine MJ, et al. Observational study of inhaled corticosteroids on outcomes for COPD patients with pneumonia. Am J Respir Crit Care Med. 2011;184:312-316.

25. Hugh-Jones P, Lambert AV. A simple standard exercise test and its use for measuring exertion dyspnoea. BMJ. 1952;1:65-71.

26. Yamauchi Y, Yasunaga H, Matsui $\mathrm{H}$, et al. Comparison of clinical characteristics and outcomes between aspiration pneumonia and community-acquired pneumonia in patients with chronic obstructive pulmonary disease. BMC Pulm Med. 2015;15:69.

27. Ohta T, Waga S, Handa W, Saito I, Takeuchi K. [New grading of level of disordered consciousness (author's transl)]. No Shinkei Geka. 1974;2: 623-627.

28. Todo T, Usui M, Takakura K. Treatment of severe intraventricular hemorrhage by intraventricular infusion of urokinase. J Neurosurg. 1991;74:81-86.

29. Mahoney FI, Barthel DW. Functional evaluation: the Barthel index. Md State Med J. 1965;14:61-65.

30. Shindo Y, Sato S, Maruyama E, et al. Comparison of severity scoring systems A-DROP and CURB-65 for community-acquired pneumonia. Respirology. 2008;13:731-735.

31. Barnes PJ. New anti-inflammatory targets for chronic obstructive pulmonary disease. Nat Rev Drug Discov. 2013;12:543-559.

32. Kellum JA, Kong L, Fink MP, et al. Understanding the inflammatory cytokine response in pneumonia and sepsis: results of the Genetic and Inflammatory Markers of Sepsis (GenIMS) Study. Arch Intern Med. 2007; 167:1655-1663.

33. Sellares J, Lopez-Giraldo A, Lucena C, et al. Influence of previous use of inhaled corticoids on the development of pleural effusion in community-acquired pneumonia. Am J Respir Crit Care Med. 2013; 187:1241-1248.

34. Barbier M, Agusti A, Alberti S. Fluticasone propionate reduces bacterial airway epithelial invasion. Eur Respir J. 2008;32:1283-1288.

35. Barnes PJ. Asthma-COPD overlap. Chest. 2016;149:7-8.

36. Hardin M, Silverman EK, Barr RG, et al; COPD Gene Investigators. The clinical features of the overlap between COPD and asthma. Respir Res. 2011;12:127.

37. Menezes AM, Montes de Oca M, Perez-Padilla R, et al. Increased risk of exacerbation and hospitalization in subjects with an overlap phenotype: COPD-asthma. Chest. 2014;145:297-304.

38. Fu JJ, Gibson PG, Simpson JL, McDonald VM. Longitudinal changes in clinical outcomes in older patients with asthma, COPD and asthmaCOPD overlap syndrome. Respiration. 2014;87:63-74.

39. Yamauchi Y, Yasunaga H, Matsui H, et al. Comparison of in-hospital mortality in patients with COPD, asthma and asthma-COPD overlap exacerbations. Respirology. 2015;20:940-946.

40. Agusti A, Calverley PM, Celli B, et al. Characterisation of COPD heterogeneity in the ECLIPSE cohort. Respir Res. 2010;11:122. 


\section{Supplementary materials Methods}

\section{Hugh-Jones dyspnea scale}

The Hugh-Jones dyspnea scale is a system for grading dyspnea severity, established by Hugh-Jones and Lambert in $1952 .{ }^{1}$ It is similar to the Medical Research Council's breathlessness scale, and is widely used in Japan. ${ }^{2}$ The dyspnea scale is defined as follows: 1) the patient's breathing is as good as that of other people of their age and build when working, walking, and climbing hills or stairs; 2) the patient is able to walk on level ground at the pace of normal people of their age and build but is unable to maintain that pace when climbing hills or stairs; 3 ) the patient is unable to keep up with normal people of their age and build on level ground but is able to walk $\sim 1.6 \mathrm{~km}$ or more at their own speed; 4) the patient is unable to walk more than $\sim 50 \mathrm{~m}$ on level ground without resting; 5) the patient is breathless when talking or undressing or is unable to leave home because of breathlessness; (unspecified) the patient is unable to be classified into the above grades because of bedridden status.

\section{Japan Coma Scale}

The Japan Coma Scale is a system widely used in $\operatorname{Japan}^{3}$ for assessing patients' levels of consciousness and is reported to correlate well with the Glasgow coma scale. ${ }^{4}$ The Japan Coma Scale is defined as follows: one-digit codes (1-3) are given to patients who are conscious without any stimuli; two-digit codes (10-30) are assigned to patients who could be aroused by some stimuli; and three-digit codes (100-300) are given to patients in coma.

\section{Barthel index}

The Barthel index is a system for grading the activities of daily life, assessing functional status and the ability to perform daily activities. ${ }^{5}$ It consists of ten factors: feeding, bathing, grooming, dressing, bowels, bladder, toilet use, transfer, mobility, and stairs. Scores range from 0 to 20, with a score of 20 indicating total independence, lower scores indicating increasing dependence, and 0 signifying complete dependence. It should be noted that changes of more than two points $(10 \%)$ in the total score accurately reflect changes in functional status. ${ }^{6}$ We categorized patients into four groups according to their score: completely independent (20); partially independent; (19-14); partially dependent (13-7); and completely dependent (6-0).

\section{BMI categories}

BMI categories were assigned based on the World Health Organization classifications of underweight $\left(<18.5 \mathrm{~kg} / \mathrm{m}^{2}\right)$, normal weight $\left(18.5-24.9 \mathrm{~kg} / \mathrm{m}^{2}\right)$, overweight $\left(25.0-29.9 \mathrm{~kg} / \mathrm{m}^{2}\right)$, and obese $\left(\geq 30.0 \mathrm{~kg} / \mathrm{m}^{2}\right)$.

\section{A-DROP scores}

The severity of pneumonia was evaluated using A-DROP scores, which use a six-point scale (0-5) to assess the clinical severity of community-acquired pneumonia. This scale was established by the Japanese Respiratory Society and is reportedly similar to the CURB-65 system of the British Thoracic Society. ${ }^{7}$ The A-DROP score consists of the following parameters: 1 ) age (male $\geq 70$ years, female $\geq 75$ years), 2) dehydration (blood urea nitrogen $\geq 21 \mathrm{mg} / \mathrm{dL}$ ), 3) respiratory failure $\left(\mathrm{SaO}_{2} \leq 90 \%\right.$ or $\left.\mathrm{PaO}_{2} \leq 60 \mathrm{mmHg}\right)$, 4) orientation disturbance (confusion), and 5) low blood pressure (systolic blood pressure $\leq 90 \mathrm{mmHg}$ ). The severity of pneumonia was classified into four categories using the A-DROP score: mild, 0 points; moderate, $1-2$ points; severe, 3 points; and extremely severe, $4-5$ points.

\section{ICD-I0 codes of comorbidities}

Comorbidities on admission were identified using ICD-10 codes: asthma (J45 and J46), interstitial pneumonia (J84), lung cancer (C34), congestive heart failure (I50), cardiac arrhythmia (I44 and I45, I47-I49), cerebrovascular disease (I60-I69), chronic liver disease (K70 and 71, K73 and 74, K76), and chronic renal failure (N18).

\section{References}

1. Hugh-Jones P, Lambert AV. A simple standard exercise test and its use for measuring exertion dyspnoea. BMJ. 1952;1:65-71.

2. Yamauchi Y, Yasunaga H, Matsui H, et al. Comparison of in-hospital mortality in patients with COPD, asthma and asthma-COPD overlap exacerbations. Respirology. 2015;20:940-946.

3. Todo T, Usui M, Takakura K. Treatment of severe intraventricular hemorrhage by intraventricular infusion of urokinase. J Neurosurg. 1991; 74:81-86.

4. Ono K, Wada K, Takahara T, Shirotani T. Indications for computed tomography in patients with mild head injury. Neurol Med Chir (Tokyo). 2007;47:291-297; discussion 7-8.

5. Mahoney FI, Barthel DW. Functional evaluation: the Barthel index. Md Med J. 1965;14:61-65.

6. Giang P, Williams A, Argyros L. Automated extraction of the Barthel Index from clinical texts. AMIA Annu Symp Proc. 2013;2013:486-495.

7. Shindo Y, Sato S, Maruyama E, et al. Comparison of severity scoring systems A-DROP and CURB-65 for community-acquired pneumonia. Respirology. 2008;13:731-735. 
International Journal of COPD

\section{Publish your work in this journal}

The International Journal of COPD is an international, peer-reviewed journal of therapeutics and pharmacology focusing on concise rapid reporting of clinical studies and reviews in COPD. Special focus is given to the pathophysiological processes underlying the disease, intervention programs, patient focused education, and self management protocols.

This journal is indexed on PubMed Central, MedLine and CAS. The manuscript management system is completely online and includes a very quick and fair peer-review system, which is all easy to use. Visit http://www.dovepress.com/testimonials.php to read real quotes from published authors 